\title{
Stage II Kidney Wilms Tumor
}

National Cancer Institute

\section{Source}

National Cancer Institute. Stage II Kidney Wilms Tumor. NCI Thesaurus. Code C7841.

Wilms tumor that is found in the kidney and in the fat, soft tissue, or blood vessels near the kidney. It may have spread to the renal sinus. The renal sinus is the part of the kidney where blood and fluid enter and exit the organ. The tumor can be completely removed with surgery. (National Wilms T umor Study Group Staging System) 